\title{
Effect of metformin on blood lipids in patients with diabetes mellitus
}

\author{
Tahniyah Haq ${ }^{1}$, Sabah $\mathrm{Haq}^{2}$ \\ ${ }^{1}$ Department of Endocrinology, Bangabandhu Sheikh Mujib Medical University, Dhaka, Bangladesh; \\ ${ }^{2}$ Farncombe Family Digestive Health Research Institute, Department of Pathology and Molecular \\ Medicine, McMaster University, Hamilton, Ontario, Canada
}

\begin{abstract}
Background and objectives: Metformin improves macrovascular complications in people with diabetes mellitus (DM). Although the exact mechanism is not known, metformin has beneficial effects on dyslipidaemia. The aim of the study was to find out if there was an effect of metformin on blood lipids in people with diabetes mellitus.
\end{abstract}

Method: This was a cross-sectional study which included 80 patients with diabetes mellitus. They were divided into 2 groups - (a) Group 1: on metformin and (b) Group 2: without metformin medication. None of the patients were on any other anti-diabetic medication. All data were obtained from patients' medical records. Individual blood lipids and lipid ratios were compared between two groups.

Result: Group 1 included 42 patients with a mean $\mathrm{HbA} 1 \mathrm{c}$ of $7.58 \pm 0.24 \%$ taking an average dose of $820.83 \pm 60.40 \mathrm{mg} /$ day of metformin. Group 2 consisted of 38 patients with mean HbA1c of $7.58 \pm 0.29 \%$. There was no significant difference in individual plasma lipid levels, lipoprotein ratio or frequency of dyslipidaemia between patients taking and not taking metformin $(p>0.05)$. Also, different doses of metformin had no significant effect on the plasma lipid levels.

Conclusion: Metformin did not affect the lipid profile of patients with diabetes mellitus.

IMC J Med Sci 2019; 13(2): 004. EPub date: 22 August 2019

\section{Introduction}

There is a multitude of evidence from both observational and intervention studies that metformin improves long-term macrovascular complications in people with type 2 diabetes mellitus [1]. It is associated with a $39 \%$ reduction in the incidence of myocardial infarction in diabetes [2]. Although, it is known that this favourable cardiovascular effect is independent of its antidiabetic action, the exact mechanism is still being studied [3].

Metformin has modest positive effects on dyslipidaemia, inflammation and thrombosis, benefiting vascular function [3]. Some studies have described that metformin lowers very low density cholesterol (VLDL), triglyceride, low density lipoprotein (LDL), plasminogen activator inhibitors, factor VIII, C-reactive protein, and increases high density lipoprotein (HDL), especially if abnormal [2]. It also stabilizes fibrin and platelets [2]. However, others show no significant effect on blood lipids [4].

The molecular mechanism by which metformin affects the lipid metabolism is still under investigation. Studies have shown that metformin (in a dose of $2300 \mathrm{mg} /$ day) reduces intestinal lipoprotein synthesis and increases glucogon like peptide 1 (GLP1), thereby reducing intestine

Address for Correspondence:

Dr. Tahniyah Haq, Assistant Professor, Department of Endocrinology, Room 1620, $15^{\text {th }}$ Floor, Block D, Bangabandhu Sheikh Mujib Medical University, Shahbag, Dhaka 1000, Bangladesh.Email: tahniyah81@gmail.com 
derived triglyceride rich plasma lipids [5]. Metformin modulates cholesterol synthesis by inhibiting 3-hydroxy-3-methyl-glutaryl-coenzyme A reductase (HMGCR) through adenosine monophosphate kinase (AMPK). This action is more pronounced in the intestine than liver, and is seen with high concentrations of metformin [6]. Recent animal studies have shown that metformin inhibits hepatic apoA5 expression, leading to the reduction of the plasma level of triglyceride (TG) in ob/ob mice [7]. Metformin also reduced postprandial hypertriglyceridemia most likely by delaying gastric emptying in mice [8]. Metformin increases cholesterol transport to HDL by up regulation of ATP binding cassette transporter. As a result, there is decreased accumulation of oxidized LDL and foam cells. In addition metformin has been shown to increase secretion of interleukin 10 which is an anti-foam cytokine [9].

Although metformin has proven cardiovascular benefits, the fact that metformin produces clinically significant improvement of blood lipids is not established. Therefore, this study was undertaken to see if there was an effect of metformin on blood lipids in ethnic Bengali people with diabetes mellitus.

\section{Methods}

This was a cross-sectional study conducted over a period of 6 months in a hospital. Study population consisted of two groups. Group-1 consisted of people with previously diagnosed diabetes mellitus (DM) taking metformin of any dose and duration. Group-2 comprised of people with DM but not on metformin medication. Group 1 was further divided into those receiving $<1000 \mathrm{mg}$ (Group 1a), and those on $\geq 1000 \mathrm{mg}$ metformin (Group 1b) per day. Individuals taking any other anti-diabetic or lipid lowering medication were excluded from the study. Information on patient's age, sex, dose of metformin, duration of diabetes, blood pressure, lipid profile and $\mathrm{HbA1c}$ were taken from their medical record. Table-1 shows cut-off values for abnormal lipids used in the study.

All values were expressed as means \pm SE or frequencies. Student's independent t-test and chisquare test were used to compare blood lipids and lipoprotein ratios between patients with and without metformin medication. One-way ANOVA was used to compare lipids between different doses of metformin. Correlation between lipid level and dose of metformin was analyzed with the Pearson's correlation coefficient test. A $p$ value of $\leq$ 0.05 was taken as significant. The SPSS version 23.0 was used for the statistical analyses.

Table-1: Cut-off values for abnormal blood lipids and lipoprotein ratios [10, 11]

\begin{tabular}{ll}
\hline $\begin{array}{l}\text { Blood lipid/ } \\
\text { lipid ratio }\end{array}$ & Cut-off for abnormal value \\
\hline Raised TC & $>220 \mathrm{mg} / \mathrm{dl}$ \\
Raised LDL & $>100 \mathrm{mg} / \mathrm{dl}$ \\
Low HDL & $<40 \mathrm{mg} / \mathrm{dl}$ (male), $<50 \mathrm{mg} / \mathrm{dl}$ (female) \\
Raised TG & $>150 \mathrm{mg} / \mathrm{dl}$ \\
Non HDL & $>130 \mathrm{mg} / \mathrm{dl}$ \\
TC:HDL ratio & $>4.5$ (male), $>4$ (female) \\
LDL:HDL ratio & $>3$ (male), $>2.5$ (female) \\
TG:HDL ratio & $>2$ \\
\hline
\end{tabular}

Note: $T C=$ total cholesterol, $T G=$ triglycerides, $H D L=$ high density lipoprotein, $L D L=$ low density lipoprotein.

\section{Result}

A total of 42 cases of DM on metformin were included in Group-1 while Group-2 had 38 DM cases who were not on metformin. The dose of metformin ranged from 500 to $1700 \mathrm{mg}$ per day, with a mean dose of $820.83 \pm 60.40 \mathrm{mg}$ per day. All patients had received advice on diet and exercise, though with variable levels of adherence. Both groups were not on any other anti-diabetic or lipid lowering medication. They were of similar age, and had comparable duration and control of diabetes. Patients taking metformin had a greater frequency of hypertension and were on antihypertensive medication including angiotensin converting enzyme inhibitor (ACEI). The baseline characteristics of the two groups are shown in Table-2.

There was no significant difference in individual plasma lipid fractions and lipoprotein ratios between patients with diabetes mellitus taking and not taking metformin ( $p>0.05$; Table-3). Also, there 
was no significant difference in the frequency of dyslipidaemia among patients with and without metformin medication ( $>0.05$; Table-4). Furthermore, there was no significant difference in plasma lipid levels and lipoprotein ratios as well as in frequencies of dislipidaemia among patients taking different doses of metformin ( $p>0.05$; Table5 and 6). No correlation between dose of metformin and plasma lipid and lipoprotein ratio was observed by Pearson's correlation analysis ( $p>0.05$; Table-7).

Table-2: Baseline characteristics of the study population $(n=80)$

\begin{tabular}{|c|c|c|}
\hline \multirow[t]{2}{*}{ Characteristics } & $\begin{array}{c}\text { Group } 1 \\
(n=42)\end{array}$ & $\begin{array}{c}\text { Group } 2 \\
(n=38)\end{array}$ \\
\hline & \multicolumn{2}{|c|}{ Mean \pm SE } \\
\hline Age (years) & $54.74 \pm 1.77$ & $46.97 \pm 1.15$ \\
\hline \multicolumn{3}{|l|}{ Sex* } \\
\hline Male & 26 (61.90\%) & $31(81.58 \%)$ \\
\hline Female & $16(38.10 \%)$ & 7 (18.42\%) \\
\hline $\begin{array}{l}\text { Duration of } \\
\text { diabetes (months) }\end{array}$ & $53.69 \pm 8.65$ & $52.45 \pm 7.96$ \\
\hline HbA1c (\%) & $7.58 \pm 0.24$ & $7.58 \pm 0.29$ \\
\hline $\begin{array}{l}\text { Dose of } \\
\text { metformin (mg) }\end{array}$ & $820.83 \pm 60.40$ & - \\
\hline Hypertension* & $22(52.38 \%)$ & $3(7.89 \%)$ \\
\hline
\end{tabular}

Table-3: Lipid profile and lipoprotein ratio of the study population $(n=80)$

\begin{tabular}{|c|c|c|c|}
\hline \multirow{2}{*}{$\begin{array}{c}\text { Lipid } \\
\text { profile } \\
\text { (mg/dl) }\end{array}$} & $\begin{array}{c}\text { Group } 1 \\
(n=42)\end{array}$ & $\begin{array}{c}\text { Group } 2 \\
(n=38)\end{array}$ & \multirow[t]{2}{*}{$\begin{array}{c}P \\
\text { value }\end{array}$} \\
\hline & \multicolumn{2}{|c|}{ Mean \pm SE } & \\
\hline$\overline{T C}$ & $185.62 \pm 5.35$ & $180.61 \pm 4.79$ & 0.49 \\
\hline LDL & $111.12 \pm 5.09$ & $109.47 \pm 4.73$ & 0.82 \\
\hline HDL & $39.95 \pm 1.88$ & $38.55 \pm 1.24$ & 0.55 \\
\hline Triglyceride & $177.79 \pm 12.45$ & $171.66 \pm 14.24$ & 0.75 \\
\hline Non HDL & $145.67 \pm 4.61$ & $142.05 \pm 4.57$ & 0.58 \\
\hline TC:HDL & $4.88 \pm 0.17$ & $4.83 \pm 0.16$ & 0.84 \\
\hline LDL:HDL & $2.89 \pm 0.14$ & $2.91 \pm 0.14$ & 0.93 \\
\hline TG:HDL & $5.03 \pm 0.47$ & $4.77 \pm 0.47$ & 0.70 \\
\hline
\end{tabular}

Table-4: Frequency of dyslipidaemia of the study population $(n=80)$

\begin{tabular}{lc|cc}
\hline \multicolumn{1}{c}{ Dyslipidaemia } & $\begin{array}{c}\text { Group 1 } \\
\text { (n=42) }\end{array}$ & $\begin{array}{c}\text { Group 2 } \\
\text { (n=38) }\end{array}$ & value \\
\cline { 2 - 3 } & \multicolumn{2}{c}{ Frequency n (\%) } & \\
\hline Raised Cholesterol & $6(14.3)$ & $4(10.5)$ & 0.61 \\
Raised LDL & $25(59.5)$ & $23(60.5)$ & 0.77 \\
Low HDL & $22(52.4)$ & $22(57.9)$ & 0.62 \\
Raised Triglyceride & $24(57.1)$ & $20(52.6)$ & 0.67 \\
Non HDL & $32(76.2)$ & $24(63.2)$ & 0.20 \\
TC:HDL & $41(97.6)$ & $37(97.4)$ & 0.94 \\
LDL:HDL & $26(63.4)$ & $28(77.8)$ & 0.17 \\
TG:HDL & $37(88.1)$ & $37(97.4)$ & 0.12 \\
\hline
\end{tabular}

Note: Chi square/Fisher's Exact test was used to calculate $p$ value. Numbers within parenthesis are percentages over column total.

Table-5: Lipid profile and lipoprotein ratio in patients receiving different doses of metformin and no metformin

\begin{tabular}{|c|c|c|c|c|}
\hline \multirow[t]{2}{*}{ Lipid profile (mg/dl) } & Group 1a $(n=23)$ & Group 1b (n=19) & Group 2 ( $n=38)$ & \multirow[t]{2}{*}{ P value } \\
\hline & \multicolumn{3}{|c|}{ Mean \pm SE } & \\
\hline Total Cholesterol & $185.04 \pm 7.46$ & $186.32 \pm 7.85$ & $180.61 \pm 29.58$ & 0.78 \\
\hline LDL & $109.96 \pm 6.43$ & $112.61 \pm 8.39$ & $109.47 \pm 28.36$ & 0.94 \\
\hline $\mathrm{HDL}$ & $40.91 \pm 2.85$ & $38.79 \pm 2.38$ & $38.55 \pm 7.66$ & 0.67 \\
\hline Triglyceride & $171.17 \pm 14.77$ & $185.79 \pm 21.23$ & $171.66 \pm 87.77$ & 0.81 \\
\hline Non HDL & $144.13 \pm 6.34$ & $147.53 \pm 6.88$ & $142.05 \pm 28.15$ & 0.80 \\
\hline TC:HDL & $4.76 \pm 0.24$ & $5.02 \pm 0.25$ & $4.83 \pm 0.99$ & 0.72 \\
\hline LDL:HDL & $2.82 \pm 0.18$ & $2.98 \pm 0.22$ & $2.91 \pm 0.85$ & 0.84 \\
\hline TG:HDL & $4.75 \pm 0.55$ & $5.36 \pm 0.82$ & $4.77 \pm 2.90$ & 0.75 \\
\hline
\end{tabular}

Note: One -way ANOVA was used to calculate $p$ values. 
Table-6: Comparative frequency of dyslipidaemia in patients receiving different doses of metformin and no metformin

\begin{tabular}{lcccc}
\hline \multicolumn{1}{c}{ Dyslipidaemia } & Group 1a (n=23) & Group 1b (n=19) & Group 2 (n=38) & \multirow{2}{*}{ P value } \\
\cline { 2 - 4 } & \multicolumn{3}{c}{ Frequency $\mathbf{n}(\mathbf{\%})$} \\
\hline Raised Cholesterol & $3(13)$ & $3(15.8)$ & $4(10.5)$ & 0.91 \\
Raised LDL & $14(60.9)$ & $11(57.9)$ & $23(60.5)$ & 0.89 \\
Low HDL & $12(52.2)$ & $10(52.6)$ & $22(57.9)$ & 0.88 \\
Raised Triglyceride & $14(60.9)$ & $10(52.6)$ & $20(52.6)$ & 0.84 \\
Non HDL & $18(78.3)$ & $14(73.7)$ & $24(63.2)$ & 0.44 \\
TC:HDL & $22(95.7)$ & $19(100)$ & $37(97.4)$ & 1 \\
LDL:HDL & $15(65.2)$ & $11(61.1)$ & $28(77.8)$ & 0.42 \\
TG:HDL & $19(82.6)$ & $18(94.7)$ & $37(97.4)$ & 0.09 \\
\hline
\end{tabular}

Note: Chi square/Fisher's Exact test was used to calculate $p$ value. Numbers within parenthesis are percentages over column total

Table-7: Correlation between dose of metformin and lipid profile/ lipoprotein ratio $(n=42)$

\begin{tabular}{lcc}
\hline \multicolumn{1}{c}{ Blood lipid (mg/dl) / lipid ratio } & $\mathbf{r}$ & $\mathbf{p}$ \\
\hline TC & 0.05 & 0.77 \\
LDL & -0.003 & 0.99 \\
HDL & 0.10 & 0.53 \\
TG & 0.06 & 0.70 \\
Non-HDL & 0.06 & 0.61 \\
TC:HDL & 0.10 & 0.93 \\
LDL:HDL & -0.04 & 0.74 \\
TG:HDL & 0.06 & 0.61 \\
\hline
\end{tabular}

Note: Pearson's correlation was used to calculate the rvalue

\section{Discussion}

Metformin has beneficial effects on cardiovascular complications. Although a number of mechanisms including action on lipids, inflammation, clotting cascade etc. have been proposed, there is still lack of clarity on the exact mechanism. This study looked at the lipid profile in patients with and without metformin, but did not find any association between dyslipidaemia and metformin use.

There was no significant difference in the lipid levels, lipoprotein ratio or frequency of dyslipidaemia between patients using and not using metformin, or taking different doses of metformin. Furthermore, there was no correlation between metformin dose and lipid levels. This finding is not in accordance with a systematic review of 41 randomized controlled trials that looked into the effect of metformin on lipid profile. This review described significant decrease of plasma triglycerides, total and LDL cholesterol with metformin, but not HDL cholesterol [12]. This beneficial effect of metformin compared to control was independent of glycaemic control (except triglyceride), body mass index, and treatment duration.

There may be several reasons why we did not find any association between lipid profile and metformin use in our study. Studies have shown that metformin reduces intestinal lipoprotein synthesis when used in high doses, of approximately $2300 \mathrm{mg} /$ day [5]. Therefore, an explanation for the lack of effect of metformin on lipid profile may be the low dose (less than 1700 $\mathrm{mg} /$ day) used by the patients in this study. Unfortunately, the duration of metformin use was not available from the database. So, we do not know if metformin had sufficient time to affect blood lipids. In randomized controlled trials to see effect of metformin on lipids, metformin was used for at least 6 weeks [12]. Some reports have indicated that the lipid lowering effect of metformin is more pronounced when baseline lipids are markedly elevated [4]. The baseline lipid levels were however not substantially elevated in this study. This may contribute to the lack of difference seen between the two groups. In case of near normal glycaemic control, metformin had no 
effect on triglycerides but still affected the tota and LDL cholesterol [12]. The HbA1c level was near normal in our study population. This may explain why a difference in triglyceride level was not found. A limitation of this study is its cross-sectional nature with small number of DM cases in both arms. This did not allow us to rigorously control the study to see the effect of introducing metformin on lipid profile. Further prospective study involving larger study population and defined criteria is needed to ascertain the effect of metformin on plasma lipids in ethnic Bengali DM population.

In conclusion, metformin had no effect on lipid profile and lipoprotein ratios in our study population.

\section{Author's contributions}

TH designed the study, collected samples, analyzed data, wrote and edited the manuscript. SH was involved in data entry and analysis.

\section{Competing interest}

There is no conflict of interest.

\section{References}

1. Campbell IW, Howlett HCS. Metformin and the heart. In: Campbell IW, Howlett HCS, Holman RR, Bailey $\mathrm{CJ}$, editors. Metformin -60 years of clinical experience. Germany: Wiley. 2017: 45-58.

2. Grant PJ. Beneficial effects of metformin on haemostasis and vascular function in man. Diabetes Metab. 2003; 29: 6S44-52.

3. Bailey CJ. Metformin: effects on micro and macrovascular complications in type 2 diabetes. Cardiovasc Drugs Ther. 2008; 22(3): 215-24.

4. Bailey CJ, Krentz AJ. Oral Antidiabetic Agents Diabetic Peripheral Neuropathy. In: Holt R I G, Cockram C S, Flyvbjerg A, Goldstein B J, editors. Textbook of Diabetes. 4th ed. Singapore: Wiley Blackwell. 2010: 615-634.
5. Jeppesen J, Zhou MY, Chen YD, Reaven GM. Effect of metformin on postprandial lipemia in patients with fairly to poorly controlled NIDDM. Diabetes Care. 1994; 17(10): 1093-9.

6. Viollet B, Guigas B, Leclerc J, Hebrard S, Lantier L, Mounier R, Andreelli F, Foretz M. AMPactivated protein kinase in the regulation of hepatic energy metabolism: from physiology to therapeutic perspectives. Acta Physiol (Oxf). 2009; 196(1): 81-98.

7. Huang $X$, Li R, Chen L, Dai W. Metformin reduces plasma triglycerides in ob/ob obese mice via inhibiting the hepatic apoA5 expression. Zhong Nan Da Xue Xue Bao Yi Xue Ban. 2017; 42(12): 1389-1394.

8. Sato D, Morino K, Nakagawa F, Murata K, Sekine O, Beppu F, Gotoh N, Ugi S, Maegawa $\mathrm{H}$. Acute effect of metformin on postprandial hypertriglyceridemia through delayed gastric emptying. Int J Mol Sci. 2017; 18(6). E1282.

9. He X, Chen X, Wang L, Wang W, Liang $Q$, Yi L, Wang $Y$, Gao $Q$. Metformin ameliorates OxLDL-induced foam cell formation in raw264.7 cells by promoting ABCG-1 mediated cholesterol efflux. Life Sci. 2019; 216: 67-74.

10. American Diabetes Association. Cardiovascular Disease and Risk Management: Standards of Medical Care in Diabetes-2019. USA: Diabetes Care; 2019; 42(1): S103-123.

11. Millán J, Pintó $X$, Muñoz $A$, Zúñiga $M$, RubiésPrat J, Pallardo LF et al. Lipoprotein ratios: Physiological significance and clinical usefulness in cardiovascular prevention. Vasc Health Risk Manag. 2009: 5:757-765.

12. Wulffelé MG1, Kooy A, de Zeeuw D, Stehouwer $\mathrm{CD}$, Gansevoort RT. The effect of metformin on blood pressure, plasma cholesterol and triglycerides in type 2 diabetes mellitus: a systematic review. J Intern Med. 2004; 256(1): 1-14. 